\title{
Family care and burden at the end of life
}

\author{
Steven H. Zarit
}

ß See related article page 1795

I $\mathrm{n}$ their article on family burden and the care of breast cancer patients (see page 1795), Grunfeld and colleagues make a fundamental and important point: family members provide a considerable amount of the care for people with terminal illnesses and their own health may suffer as a consequence. ${ }^{1}$ In their study of 89 caregivers of women with advanced breast cancer, caregivers were significantly more anxious than patients and were substantially more likely to be depressed. The caregivers reported a considerable increase in burden and depression by the time the patients reached the terminal stage of illness. Over three-quarters of those who were employed reported that they had to miss work because of their caregiving responsibilities.

Care at the end of life has been overlooked in the literature on family caregiving, perhaps because its duration is relatively brief compared with the assistance given to people with diseases such as Alzheimer's that can span a decade or more. In those long-term care conditions, caregiving has a dramatic impact on the health and well-being of family caregivers. Between $40 \%$ and $70 \%$ of caregivers have been found to have clinically significant levels of depressive symptoms, and as many as $50 \%$ may meet criteria for a diagnosable depressive disorder at some point in their caregiving careers. ${ }^{2-7}$ Caregivers have been found to have an elevated risk of death compared with age- and sex-matched control subjects who are not providing care. ${ }^{8}$ The work done by Grunfeld and colleagues, along with other recent studies, ${ }^{9,10}$ demonstrates that risks to health and well-being for caregivers assisting relatives at the end of life are similar to risks for caregivers in long-term care situations.

These studies of the adverse effects of caregiving underscore the central role that families play in the care of people with a disease or disability. Although families have always cared for sick family members, both cultural and medical practice factors have made these responsibilities more difficult. Notable changes in family life such as increased participation in the work place and decreased family size mean that there are fewer family members available to provide care. Those who are available may very likely have to work outside the home. In the area of medical care, decreasing length of hospital stays and decreased coverage for home health services result in families having to take on new tasks (e.g., providing intravenous medications, taking care of bladder catheters and managing home oxygen) that were previously performed by health care personnel. Even in countries such as Sweden, that are generally known for providing services to people at home, families are being asked to provide more of the care. ${ }^{11}$

In these circumstances, we need to consider family caregivers and be concerned about them for 2 reasons. First, family caregivers must be recognized as an essential part of the treatment team. By clearly recognizing this role, physicians and other health care providers encourage caregivers to be more confident about their abilities to care for their loved ones. Further, without their assistance, or with a faltering assistance, not only will the societal costs of chronic and terminal care be substantially greater, but the wellbeing and perhaps even the survival rates of patients will be much poorer. Second, physicians and other health care providers need to be alert to the heavy burden that such care places on caregivers. The burden of care should be assessed, stress levels and mental health monitored (especially for depressive symptoms) and appropriate steps taken to prevent caregivers from becoming overwhelmed.

These caregiver needs must be addressed in a sensitive way, with interventions that support caregivers emotionally and in the performance of their care activities. In a comprehensive review of caregiving for terminally ill patients, Haley ${ }^{12}$ described several promising strategies for helping families. A fundamental step is providing families with the information they need to understand the patient's illness and manage the various tasks required of them. They may benefit from learning how to communicate better with the patient, as well as examining their own role, including the ups and downs they are facing and the possibility of finding rewards or satisfaction in what they are doing. Getting help with care tasks in the home may be useful in reducing their level of stress. Haley also pointed out that, although many people receive help with their grief after the patient's death, some caregivers are largely overlooked, such as those who cared for a relative in a nursing home.

These approaches are straightforward, but they depend on having a psychologist or other health care professional familiar with end-of-life care included as part of the treatment team. Although time and effort are required, these strategies may help caregivers provide the care they want to and provide better home care at a reduced risk to their own health. There may even be a potential for costsavings: caregivers who are more knowledgeable and confident may place fewer demands on the physician and other health care providers. 
Steven Zarit is Professor and Head, Department of Human Development and Family Studies, Pennsylvania State University, University Park, Penn.

Competing interests: None declared.

\section{References}

1. Grunfeld E, Coyle D, Whelan T, Clinch J, Reyno L, Earle CC, et al. Family caregiver burden: results of a longitudinal study of breast cancer patients and their principal caregivers. CMA7 2004;170(12):1795-801.

2. Friss LR, Whitlatch CJ. Who's taking care? A statewide study of family caregivers. Am 7 Alzheimers Care Related Dis Res 1991;6:16-26.

3. Gallagher D, Rose J, Rivera P, Lovett S, Thompson LW. Prevalence of depression in family caregivers. Gerontologist 1989;29:449-56.

4. Pruchno RA, Resch NL. Aberrant behaviors and Alzheimer's disease: mental health effects on spouse caregivers. 7 Gerontol 1989;44(5): S177-S82.

5. Redinbaugh EM, MacCallum RC, Kiecolt-Glaser JK. Recurrent syndroma depression in caregivers. Psychol Aging 1995;10:358-68.

6. Schulz R, O'Brien AT, Bookwala J, Fleissner K. Psychiatric and physical morbidity effects of dementia caregiving: prevalence, correlates, and causes.
Gerontologist 1995;35:771-91.

7. Whitlatch CJ, Feinberg LF, Sebesta DS. Depression and health in family caregivers: adaptation over time. F Aging Health 1997;9(2):222-43.

8. Schulz R, Beach SR. Caregiving as a risk factor for mortality: the Caregiver Health Effects Study. 7AMA 1999;282:2215-9.

9. Haley WE, LaMonde LA, Han B, Burton AM, Schonwetter R. Predictors of depression and life satisfaction among spousal caregivers in hospice: application of a stress process model. 7 Palliat Med 2003;6:215-24.

10. Rabow MW, Hauser JM, Adams J. Supporting family caregivers at the end of life: "They don't know what they don't know." 7AMA 2004;291:483-91.

11. Sundström G, Johansson L, Hassing LB. The shifting balance of long-term care in Sweden. Gerontologist 2002;42:350-5.

12. Haley WE. The costs of family caregiving: implications for geriatric oncology. Crit Rev Oncol Hematol 2003;48(2):151-8.

Correspondence to: Steven Zarit, Department of Human

Development and Family Studies, 211 Henderson Building

South, Pennsylvania State University, University Park, PA 16802-

6505, USA; fax 814 863-7963; z67@psu.edu

\section{Charging the patient to save the system? Like bailing water with a sieve}

\section{Stephen Birch}

$\mathrm{H}$ ow can you tell the age of a Canadian? By the number of times they have heard Canadian politicians claim that publicly funded health care, free at the point of delivery, is not sustainable and that the survival of the health care system is dependent on the introduction of "patient participation" in meeting the costs of health care. In an age of evidence-based health policy, these claims stand out as a beacon of political hypocrisy and intellectual dishonesty, disregarding both the theoretical reasons and empirical evidence that support first-dollar coverage of health care as a key determinant of the efficient use of health care resources. ${ }^{1-6}$

On what basis can it be argued that charging patients for health care will save the system? Will it generate muchneeded additional resources to support the health care needs of an aging population? Will it reduce inefficiency by deterring people from visiting physicians unnecessarily? Will it free up much-needed resources to serve those in need, fund other public programs or reduce taxes? Finally, how will the health care system be configured under a regime of patient fees?

Suppose the next federal government were to amend the Canada Health Act to provide provincial administrations with the power to charge patients for insured services without loss of federal transfers. Based on health policies for access to many noninsured services in most provinces, provisions would be made so that certain groups would be exempt from the charges. Families on welfare, elderly people and, possibly, children might expect that they are protected from these charges because their ability to pay is compromised by their place in society. For example, according to Statistics Canada data for 2003, of Canada's 31.5 million residents, over 11 million are either children ( $\leq 19$ years) or elderly ( $\geq 65$ years) and another 3 million are unemployed (see www.statcan.ca /english/Pgdb/demo10a.htm and www.statcan.ca/english /Pgdb/labor07a.htm). Even without considering the working poor, almost half of the population would probably escape charges. Moreover, of the more than 7 million bed-days in acute care hospitals in Ontario, less than one third were occupied by adults under the age of 60 in $2002 . .^{7}$ In other words, only a relatively small proportion of all contacts would qualify for a charge. So, if we look on patient charges as a type of health-user tax, the tax base immediately shrinks. To raise any particular revenue target from patient charges, the level of charge must be substantial for those users who do not qualify for exemption. Hence, sustainable revenue streams from user charges will depend on a stream of chronically sick nonpoor adults. But the chronically sick are at a higher risk for unemployment and poverty, which means that they are likely to become exempt from charges. In addition, new administrative procedures would need to be set up to determine eligibility for exemption status and to collect fees. In the absence of expanding the number of administrators in health care, an increasing proportion of physi- 